\title{
Review Article \\ Significant Remote Sensing Vegetation Indices: A Review of Developments and Applications
}

\author{
Jinru Xue and Baofeng Su \\ College of Mechanical and Electronic Engineering, Northwest A\&F University, Yangling, Shaanxi 712100, China \\ Correspondence should be addressed to Baofeng Su; bfs@nwsuaf.edu.cn
}

Received 24 January 2017; Accepted 13 April 2017; Published 23 May 2017

Academic Editor: Chenzong Li

Copyright (C) 2017 Jinru Xue and Baofeng Su. This is an open access article distributed under the Creative Commons Attribution License, which permits unrestricted use, distribution, and reproduction in any medium, provided the original work is properly cited.

\begin{abstract}
Vegetation Indices (VIs) obtained from remote sensing based canopies are quite simple and effective algorithms for quantitative and qualitative evaluations of vegetation cover, vigor, and growth dynamics, among other applications. These indices have been widely implemented within RS applications using different airborne and satellite platforms with recent advances using Unmanned Aerial Vehicles (UAV). Up to date, there is no unified mathematical expression that defines all VIs due to the complexity of different light spectra combinations, instrumentation, platforms, and resolutions used. Therefore, customized algorithms have been developed and tested against a variety of applications according to specific mathematical expressions that combine visible light radiation, mainly green spectra region, from vegetation, and nonvisible spectra to obtain proxy quantifications of the vegetation surface. In the real-world applications, optimization VIs are usually tailored to the specific application requirements coupled with appropriate validation tools and methodologies in the ground. The present study introduces the spectral characteristics of vegetation and summarizes the development of VIs and the advantages and disadvantages from different indices developed. This paper reviews more than 100 VIs, discussing their specific applicability and representativeness according to the vegetation of interest, environment, and implementation precision. Predictably, research, and development of VIs, which are based on hyperspectral and UAV platforms, would have a wide applicability in different areas.
\end{abstract}

\section{Introduction}

Remote sensed information of growth, vigor, and their dynamics from terrestrial vegetation can provide extremely useful insights for applications in environmental monitoring, biodiversity conservation, agriculture, forestry, urban green infrastructures, and other related fields. Specifically, these types of information applied to agriculture provide not only an objective basis (depending on resolution) for the macroand micromanagement of agricultural production but also in many occasions the necessary information for yield estimation of crops [1]. These latter applications have been developed to be a well-known discipline category, precision agriculture, which could be tracked back to three decades ago [1]. However, the applicability of remote sensing and its different VIs extracted from these techniques usually relies heavily on the instruments and platforms to determine which solution is best to get a particular issue.
1.1. Remote Sensing Platform Considerations. In terms of platforms, the advantages of satellite based remote sensing include high spatial resolution, which makes possible the extraction of long time data series of consistent and comparable data, which can be cost effective [2]. Furthermore, some satellite platforms have free access to visible and multispectral data, such as Landsat 7-8. However, there are two main problems with these platforms for precision agriculture applications, which are related to the per pixel resolution $\left(30 \mathrm{~m}^{2}\right.$ per pixel for Landsat and $500 \mathrm{~m}^{2}$ for MODIS) and the orbit period (16 d for Landsat and $26 \mathrm{~d}$ for SPOT). More recently, pixel resolution has been increased by newer satellites, such as WorldView-2 and -3 (DigitalGlobe, Longmont, CO, USA). WorldView-2 was the first commercial high resolution satellite to provide eight spectral sensors in the visible to near infrared range. Along with the four typical multispectral bands: blue $(450-510 \mathrm{~nm})$, green $(510-580 \mathrm{~nm})$, red $(630-$ $690 \mathrm{~nm})$, and near infrared (NIR) (770-895 nm), each sensor 
is narrowly focused on a particular range of the electromagnetic spectrum that is sensitive to a particular feature from the ground or a property of the atmosphere. However, images from this platform can be cost prohibitive for long time data series studies.

The second problem with satellite based remote sensing is the revisitation time, which is 16 days in average, which makes the agricultural applications difficult, specifically those related to water and nutrient management. Moreover, passive sensors cannot penetrate clouds; therefore, there is no usable data capture for overcast days.

To solve these two main problems, airborne and more recently UAV platforms can be used. The former can also be cost prohibitive due to the requirement of expensive aircrafts and pilots. The latter has become almost of ubiquitous use in the last five years with affordable aircrafts and camera payloads ranging from visible, near and thermal infrared, and 3D LIDAR, which has been referred to as Unmanned Aerial System (UAS). Among UAS platforms, there are mainly fixed wing and multirotor options available. There is a compromise using these UAS platforms in relation to payload weight versus flying time. In general, longer flying time achieved by fixed wing systems demands lighter weight payloads. For example, small high definition visible cameras weighting less than 300 grams as payload of a fixed wing UAS allow it to fly for around two hours using currently available batterypower [3]. On the contrary, battery-powered multirotor UAS with higher payload capacity have reduced fly time that at the moment is around 15- to 25-minute duration. Using these UAS, higher spatial and temporal data resolution can be achieved, which makes possible precision agriculture applications to the submeter resolution per pixel. This allows research and practical applications applied to growth and vigor dynamic assessment, plant water status sensing for irrigation scheduling applications, and evapotranspiration modelling, among others [4-9].

1.2. Remote Sensing and Vegetation Indices. Remote sensing of vegetation is mainly performed by obtaining the electromagnetic wave reflectance information from canopies using passive sensors. It is well known that the reflectance of light spectra from plants changes with plant type, water content within tissues, and other intrinsic factors [10]. The reflectance from vegetation to the electromagnetic spectrum (spectral reflectance or emission characteristics of vegetation) is determined by chemical and morphological characteristics of the surface of organs or leaves [3]. The main applications for remote sensing of vegetation are based on the following light spectra: (i) the ultraviolet region (UV), which goes from 10 to $380 \mathrm{~nm}$; (ii) the visible spectra, which are composed of the blue $(450-495 \mathrm{~nm})$, green $(495-570 \mathrm{~nm})$, and red $(620-750 \mathrm{~nm})$ wavelength regions; and (iii) the near and mid infrared band $(850-1700 \mathrm{~nm})[11,12]$. The emissivity rate of the surface of leaves (equivalent to the absorptivity in the thermal waveband) of a fully grown green plant without any biotic or abiotic stress is generally in the range of 0.96-0.99 and is more often between 0.97 and 0.98 [13]. On the contrary, for dry plants, the emissivity rate generally has a larger range going from 0.88 to 0.94 [13]. Vegetation emissivity in the near and mid infrared regions has been widely studied within plant canopies. Indices extracted from this light spectra range can be attributed to a range of characteristics beyond growth and vigor quantification of plants related to water content, pigments, sugar and carbohydrate content, protein content, and aromatics, among others $[2,14]$. Different applications are dependent on the reflectivity peaks or overtones for specific compounds within the visible and near/mid infrared regions of light spectra $[14,15]$. Plant reflectivity in the thermal infrared spectral range $(8-14 \mu \mathrm{m})$ follows the blackbody radiation law [16], which allows interpreting plant emission as directly related to plant temperature. Hence, indices obtained from this spectra range can be used as a proxy to assess stomata dynamics that regulates transpiration rate of plants. Therefore, the later indices can be used as indicator of plant water status [17-19] and abiotic/biotic stress levels [20, 21].

The latter considerations demonstrate that the quantitative interpretation of remote sensing information from vegetation is a complex task. Many studies have limited this interpretation by extracting vegetation information using individual light spectra bands or a group of single bands for data analysis. Thus, researchers often combine the data from near infrared $(0.7-1.1 \mathrm{~m})$ and red $(0.6-0.7 \mathrm{~m})$ bands in different ways according to their specific objectives [2]. These types of combinations present many disadvantages (e.g., lack of sensitivity) by using single or limited group of bands to detect, for example, vegetation biomass. These limitations are particularly evident when trying to apply these types of VI on heterogeneous canopies, such as horticultural tree plantations. A mixed combination of soils, weeds, cover crops in the interrow, and the plants of interest makes the discrimination regions of interest and extraction of simple VI very difficult, specifically, when the vegetation of interest has different VIs due to spatial variability, or VIs corresponding to other vegetation (weeds and cover crop), which can be similar to those of interest. The later will complicate imaging denoising and filtering processes. Several image analysis techniques and algorithms have been developed to go around these issues, which will be described later. Even though there are many considerations as described before, the construction of simple VI algorithm could many times render simple and effective tools to measure vegetation status on the surface of the Earth [6].

\section{Vegetation Indices and Validation Process}

With the use of high resolution spectral instrumentation, the number of bands obtained by remote sensing is increasing, and the bandwidth is getting narrower [7]. One of the most used and implemented indices calculated from multispectral information as normalized ratio between the red and near infrared bands is the Normalized Difference Vegetation Index (NDVI) [22]. A direct use of NDVI is to characterize canopy growth or vigor; hence, many studies have compared it with the Leaf Area Index (LAI) [23], where LAI is defined as the area of single sided leaves per area of soil [24].

Vegetation information from remote sensed images is mainly interpreted by differences and changes of the green leaves from plants and canopy spectral characteristics. The 
most common validation process is through direct or indirect correlations between VIs obtained and the vegetation characteristics of interest measured in situ, such as vegetation cover, LAI, biomass, growth, and vigor assessment. More established methods are used to assess VIs using direct and georeferenced methods by monitoring sentinel plants to be compared with VIs obtained from the same plants for calibration purposes.

The later process is known as allometric measurements and requires destructive methods to scan specific area of total leaves per plant or tree in the case of LAI [25]. Indirect validation methods are based on proximal instrumentation using the same or similar spectral instrumentation to assess georeferenced sentinel plants at the same angle as the aerial platforms. The latter method is useful to compare VIs obtained from satellite that are sensitive to atmospheric effects and serve as a mean to obtain correction factors. More recent indirect methods based on cover photography to estimate canopy cover, LAI, porosity, and clumping index have used automated analysis methods.

For this purpose, upward looking cover photogrammetry at zero zenith angle is taken with visible cameras to obtain canopy architecture parameters calculated using computer vision algorithms. An automated image acquisition and calculation method was proposed by Fuentes et al. 2008 applied to Eucalyptus trees [26] and it has been successfully applied for other crops such as grapevines compared to allometric measurements and to validate NDVI calculated from satellite information (WorldView-2) [27], apple trees with increased accuracy by using a variable light extinction coefficient $(k)$ [28], and cherry trees improving the method by extracting nonleaf material such as branches for tall trees [29, 30]. In late 2015, a computer application (App) for smartphones and tablet PCs called VitiCanopy was released for free use to assess canopy architecture parameters using the cover photography automated algorithms, which can be applied to any other tree crop by changing to a specific $k$ value [31,32]. Other Apps using RGB photogrammetry to assess LAI have been later developed such as PoketLAI [33-35].

2.1. Basic Vegetation Indices. Jordan [36] proposed in 1969 one of the first VIs named Ratio Vegetation Index (RVI), which is based on the principle that leaves absorb relatively more red than infrared light; RVI can be expressed mathematically as

$$
\mathrm{RVI}=\frac{R}{\mathrm{NIR}}
$$

where NIR is the near infrared band reflectance and $R$ is red band reflectance. According to the spectral characteristics of vegetation, bushy plants have low reflectance on the red band and have shown a high correlation with LAI, Leaf Dry Biomass Matter (LDBM), and chlorophyll content of leaves [37]. The RVI is widely used for green biomass estimations and monitoring, specifically, at high density vegetation coverage, since this index is very sensitive to vegetation and has a good correlation with plant biomass. However, when the vegetation cover is sparse (less than $50 \%$ cover), RVI is sensitive to atmospheric effects, and their representation of biomass is weak.

The Difference Vegetation Index (DVI) was proposed later [38] and can be expressed as

$$
\mathrm{DVI}=\mathrm{NIR}-R \text {. }
$$

The DVI is very sensitive to changes in soil background; it can be applied to monitoring the vegetation ecological environment. Thus, DVI is also called Environmental Vegetation Index (EVI).

The Perpendicular Vegetation Index (PVI) [38] is a simulation of the Green Vegetation Index (GVI) in $R$, NIR 2D data. In the NIR $-R$ coordinate system, the spectral response from soil is presented as a slash (soil brighten line). The latter effect can be explained as the soil presents a high spectral response in the NIR and $R$ bands. The distance between the point of reflectivity $(R, N I R)$ and the soil line has been defined as the Perpendicular VI, which can be expressed as follows:

$$
\mathrm{PVI}=\sqrt{\left(\rho_{\text {soil }}-\rho_{\mathrm{veg}}\right)_{R}^{2}-\left(\rho_{\text {soil }}-\rho_{\mathrm{veg}}\right)_{\mathrm{NIR}}^{2}}
$$

where $\rho_{\text {soil }}$ is the soil reflectance; $\rho_{\mathrm{veg}}$ is the vegetation reflectivity; PVI characterizes the vegetation biomass in $\rho_{\text {red }}$ the soil background; the greater the distance, the greater the biomass.

PVI can also be quantitatively expressed as

$$
\mathrm{PVI}=\left(\mathrm{DN}_{\mathrm{NIR}}-b\right) \cos \theta-\mathrm{DN}_{R} * \sin \theta,
$$

where $\mathrm{DN}_{\mathrm{NIR}}$ and $\mathrm{DN}_{R}$ are the radiation reflected luminance values from the NIR and $R$, respectively; $b$ is the intercept of the soil baseline and the vertical axis of NIR reflectivity; and $\theta$ is the angle between the horizontal axis of $R$ reflectivity and soil baseline. PVI filters out in this way the effects of soil background in an efficient manner; PVI also has less sensitivity to atmospheric effects and it is mainly used for the inversion of surface vegetation parameter (grass yield, chlorophyll content), the calculation of LAI, and vegetation identification and classification $[39,40]$. However, PVI is sensitive to soil brightness and reflectivity, especially in the case of low vegetation coverage and needs to be adjusted for this effect [41].

As mentioned before, the Normalized Difference Vegetation Index (NDVI) is the most widely used as VI; it was proposed by Rouse Jr. et al. [42], which can be expressed as

$$
\mathrm{NDVI}=\frac{\left(\rho_{\mathrm{NIR}}-\rho_{R}\right)}{\rho_{\mathrm{NIR}}}+\rho_{R} .
$$

Since the index is calculated through a normalization procedure, the range of NDVI values is between 0 and 1 , having a sensitive response to green vegetation even for low vegetation covered areas. This index is often used in research related to regional and global vegetation assessments and was shown to be related not only to canopy structure and LAI but also to canopy photosynthesis $[43,44]$. However, NDVI is sensitive to the effects of soil brightness, soil color, atmosphere, cloud and cloud shadow, and leaf canopy shadow and requires remote sensing calibration. 
2.2. Vegetation Indices considering Atmospheric Effects. Given the limitations of NDVI under atmospheric effects, Kaufman and Tanré [40] proposed the Atmospherically Resistant Vegetation Index (ARVI). This index is based on the knowledge that the atmosphere affects significantly $R$ compared to the NIR. Thus, Kaufman and Tanré modified the radiation value of $R$ by the difference between the blue $(B)$ and $R$. Therefore, ARVI can effectively reduce the dependence of this VI to atmospheric effects, which can be expressed as

$$
\begin{aligned}
\operatorname{ARVI} & =\frac{(\mathrm{NIR}-R B)}{(\mathrm{NIR}+R B)}, \\
\rho_{r b}^{*} & =\rho_{\tau}^{*}-\gamma\left(\rho_{b}^{*}-\rho_{\tau}^{*}\right),
\end{aligned}
$$

where $R B$ is the difference between $B$ and $R$, is the reflectivity related to the molecular scattering and gaseous absorption for ozone corrections, and represents the air conditioning parameters.

The ARVI is commonly used to eliminate the effects of atmospheric aerosols. The aerosols and ozone effects in the atmosphere still need to be eliminated by the $5 \mathrm{~S}$ atmospheric transport model [45]. However, to implement the 5S atmospheric transmission model, actual atmospheric parameters must be considered, which are difficult to obtain. If the ARVI index is not calculated using the $5 \mathrm{~S}$ model, this index is not expected to perform much better than NDVI considering atmospheric effects or large dust particles in the atmosphere. Thus, Zhang et al. [46] proposed a new atmospheric effect resistant vegetation index, namely, IAVI, that can eliminate atmospheric interference without the use of the $5 \mathrm{~S}$ model.

$$
\text { IAVI }=\frac{\left\{\rho_{\text {nir }}-\left[\rho_{r}-\gamma\left(\rho_{b}-\rho_{r}\right)\right]\right\}}{\left\{\rho_{\text {nir }}+\left[\rho_{r}-\gamma\left(\rho_{b}-\rho_{r}\right)\right]\right\}},
$$

where the range of $\gamma$ values is between 0.65 and 1.12; a significant value of $\gamma$ is close to 1 for ARVI. After testing, the error caused in IAVI by the atmosphere effect is between $0.4 \%$ and $3.7 \%$, which is less than those found when using NDVI in the same conditions (14-31\%).

2.3. Adjusted-Soil Vegetation Index. The distinction of vegetation from the soil background was originally proposed by Richardson and Wiegand [47] by analyzing the soil line, which can be considered as a linear relationship on the $2 \mathrm{D}$ plane of the soil spectral reflectance values between the NIR and $R$. Therefore, it can be considered as a comprehensive description of a large number of soil spectral information from a number of environments [48]. Many VIs that take into account the effect of soil background have been based on this principle. In addition to PVI ((3)-(4)), the Soil Line Atmospheric Resistance Index (SLRA) was developed based on the improvement of the soil line principle. The SLRA was then combined with the Transformed Soil-Adjusted Vegetation Index (TSAVI) to develop the Type Soil Atmospheric Impedance Vegetation Index (TSARVI) [49], which will be discussed later.

As shown before, NDVI (5) is very sensitive to background factors, such as the brightness and shade of the vegetation canopies and soil background brightness. Researches have shown that when the background brightness is increased, NDVI also increases systematically. Given the effect of soil background, $R$ radiation increases significantly when the vegetation cover is sparse; conversely NIR radiation is reduced to make the relationship between vegetation and soil more sensible. Many VIs have been developed to adjust to the soil effect.

Since NDVI and PVI have some deficiencies in describing the spectral behavior of vegetation and soil background, Huete [50] established the Soil-Adjusted Vegetation Index (SAVI), which can be expressed as follows:

$$
\text { SAVI }=\frac{\left(\rho_{n}-\rho_{r}\right)(1+L)}{\left(\rho_{n}+\rho_{r}+L\right)} .
$$

The above model of a soil vegetation system was established to improve the sensitivity of NDVI to soil backgrounds, where $L$ is the soil conditioning index, which improves the sensitivity of NDVI to soil background. The range of $L$ is from 0 to 1 . In practical applications, the values of $L$ are determined according to the specific environmental conditions. When the degree of vegetation coverage is high, $L$ is close to 1 , showing that the soil background has no effect on the extraction of vegetation information. This kind of ideal conditions is rarely found in natural environments and can be applicable only in the case of a large canopy density and coverage [40]. The value of $L$ is around 0.5 under most common environmental conditions. When $L$ is close to 0 , the value of SAVI is equal to NDVI. However, $L$ factor should vary inversely with the amount of vegetation present to obtain the optimal adjustment for the soil effect. Thus, a modified SAVI (MSAVI) replaces $L$ factor in the SAVI equation (8) with a variable $L$ function. In this way, MSAVI [51] reduces the influence of bare soil on SAVI, which can be expressed as follows:

$$
\begin{aligned}
& \text { MSAVI }=0.5 *\left\{2 R_{800}+1\right. \\
& \left.\quad-\text { SQRT }\left[\left(2 R_{800}+1\right)^{2}-8\left(R_{800}-R_{670}\right)\right]\right\} .
\end{aligned}
$$

The SAVI is much less sensitive than the RVI (1) to changes in the background caused by soil color or surface soil moisture content. Three new versions of SAVI (SAVI2, SAVI3, and SAVI4) were developed based on the theoretical considerations of the effects of wet and dry soils [41]. SAVI2, SAVI3, and SAVI4 reduce the effect of background soil brightness, by taking into account the effect of the variation of the solar incidence angle and changes in the soil physical structure.

Based on the implementation of the MSAVI, Richardson and Wiegand (1977) proposed a Modified Secondary SoilAdjusted Vegetation Index (MSAVI2) [47], which can be expressed as

\section{MSAVI2}

$$
\begin{aligned}
= & 0.5 \\
& *\left[(2 \mathrm{NIR}+1)-\sqrt{(2 \mathrm{NIR}+1)^{2}-8(\mathrm{NIR}-\mathrm{R})}\right] .
\end{aligned}
$$


MSAVI2 does not rely on the soil line principle and has a simpler algorithm; it is mainly used in the analysis of plant growth, desertification research, grassland yield estimation, LAI assessment, analysis of soil organic matter, drought monitoring, and the analysis of soil erosion [39].

Baret et al. studied the sensitivity of five VIs (NDVI, SAVI, Transformed Soil-Adjusted Vegetation Index (TSAVI), Modified Soil-Adjusted Vegetation Index (MSAVI), and Global Environment Monitoring Index (GEMI)) to the soil background. They simulated the performance of the VIs for different soil textures, moisture levels, and roughness by using the Scattering from Arbitrarily Inclined Leaves (SAIL) model. They determined an optimum value of SAIL $=0.16$ to reduce the effects of soil background and then proposed an Optimized Soil-Adjusted Vegetation Index (OSAVI) [48] that can be expressed as follows:

$$
\text { OSAVI }=\frac{(\mathrm{NIR}-R)}{(\mathrm{NIR}+R+X)}
$$

where SAIL is 0.16 and OSAVI does not depend on the soil line and can eliminate the influence of the soil background effectively. However, the applications of OSAVI are not extensive; it is mainly used for the calculation of aboveground biomass, leaf nitrogen content, and chlorophyll content, among others [52].

2.4. Tasseled Cap Transformation of Greenness Vegetation Index (GVI, YVI, and SBI). Kauth and Thomas studied the spectral pattern of the vegetation growth process and called it the "spike cap" pattern, including the soil background reflectivity and brightness line. The Tasseled Cap Transformation is a conversion of the original bands of an image into a new set of bands with defined interpretations that are useful for vegetation mapping. A Tasseled Cap Transformation is performed by taking "linear combinations" of the original image bands, which is similar in concept to the multivariate data analysis technique called principal components analysis (PCA) [53].

The Tasseled Cap can convert Landsat MSS, Landsat TM, and Landsat 7 ETM data. For Landsat MSS data, furthermore, the Tasseled Cap performs orthogonal transformation on the original data, which converts it into a $4 \mathrm{D}$ space. This conversion includes the Soil Brightness Index (SBI) (14), degree of Green Vegetation Index (GVI) (12), and the degree of Yellow Vegetation Index (YVI) (13). It also includes Nonsuch Index (NSI) mainly for noise reduction. The NSI is closely related to atmospheric effects. For the Landsat 5 TM data, the Tasseled Cap results consist of three factors: brightness, greenness, and a third component related to soil. Among them, the brightness and the greenness are equivalent to SBI and GVI in the MSS Tasseled Cap. The third component is related to soil characteristics and humidity. For Landsat 7 ETM data, the Tasseled Cap Transformation generates six bands, namely, brightness, greenness, humidity, the fourth component (noise), a fifth component, and a sixth component.

$$
\begin{aligned}
\mathrm{GVI}= & -0.290 \mathrm{MSS}_{4}-0.562 \mathrm{MSS}_{5}+0.600 \mathrm{MSS}_{6} \\
& +0.491 \mathrm{MSS}_{7}
\end{aligned}
$$

$$
\begin{aligned}
\mathrm{YVI}= & -0.829 \mathrm{MSS}_{4}-0.522 \mathrm{MSS}_{5}+0.039 \mathrm{MSS}_{6} \\
& +0.149 \mathrm{MSS}_{7} \\
\mathrm{SBI}= & +0.433 \mathrm{MSS}_{4}-0.632 \mathrm{MSS}_{5}+0.586 \mathrm{MSS}_{6} \\
& +0.264 \mathrm{MSS}_{7} .
\end{aligned}
$$

The GVI, YVI, and SBI ignore the interaction and effects of the atmosphere, soil, and vegetation. SBI and GVI can be used to evaluate the behavior of vegetation and bare soil [54]. The GVI has a strong correlation with different vegetation covers. Thus, GVI increases the processing of atmospheric effects. Jackson et al. (1980) proposed the Adjust Soil Brightness Index (ASBI) and Adjust Green Degree Vegetation Index (AGVI) [55], which can be expressed as follows:

$$
\begin{aligned}
\mathrm{ASBI} & =2.0 \mathrm{YVI}, \\
\mathrm{AGVI} & =\mathrm{GVI}-(1+0.018 \mathrm{GVI}) \mathrm{YVI}-\frac{\mathrm{NSI}}{2} .
\end{aligned}
$$

Misra and Wheeler (1977) performed PCA of Landsat images and computed the multiple factors of these indexes. This analysis was the basis of the development of the Misra Soil Brightness Index (MSBI), Misra Green Degree Vegetation Index (MGVI), and Misra Yellow Degree Vegetation Index (MYVI) [56], which can be expressed as follows:

$$
\begin{aligned}
\text { MSBI }= & 0.406 \mathrm{MSS}_{4}+0.60 \mathrm{MSS}_{5}+0.645 \mathrm{MSS}_{6} \\
& +0.243 \mathrm{MSS}_{7}, \\
\mathrm{MGVI}= & -0.386 \mathrm{MSS}_{4}-0.53 \mathrm{MSS}_{5}+0.535 \mathrm{MSS}_{6} \\
& +0.532 \mathrm{MSS}_{7}, \\
\mathrm{MYVI}= & 0.723 \mathrm{MSS}_{4}-0.597 \mathrm{MSS}_{5}+0.206 \mathrm{MSS}_{6} \\
& -0.278 \mathrm{MSS}_{7} .
\end{aligned}
$$

Since NDVI has been found to be affected only by soil brightness, it presents a negative correlation between NDVI and soil brightness. A positive correlation is found when only atmospheric effects affect NDVI. Under natural conditions, the soil and atmosphere influence NDVI in a complex manner, which interacts with the vegetation cover influence. Therefore, atmosphere and vegetation have a collective effect on NDVI based on the soil characteristics and exposure. Liu and Huete comprehensively analyzed multiple soil types and atmospheric enhanced VIs. They developed the Atmosphere Antivegetation Index (ARVI) and Soil-Adjusted Vegetation Index (SAVI) for a comprehensive analysis of vegetation in these conditions. They found that, as a result of the interaction between the soil and the atmosphere, reducing one of them may increase the other. They introduced a feedback mechanism by building a parameter to simultaneously correct soil 
and atmospheric effects. This parameter is the Enhanced Vegetation Index (EVI) [57] that can be expressed as follows:

$$
\begin{aligned}
& \mathrm{EVI}=\frac{\left(\mathrm{TM}_{4}-\mathrm{TM}_{3}\right)(1+L)}{\mathrm{TM}_{4}-C_{1} \mathrm{TM}_{3}+C_{2} \mathrm{TM}+L}, \\
& \mathrm{EVI}=2.5 * \frac{\rho_{n}^{*}-\rho_{r}^{*}}{\rho_{n}^{*}+C_{1} \rho_{r}^{*}-C_{2} \rho_{b}^{*}+L},
\end{aligned}
$$

which includes the values of NIR, $R$, and $B$, which are corrected by the atmosphere; $L$ represents soil adjustment parameters, and its value is equal to 1 ; and parameters correspond to constant values equivalent to 6 and 7.5, respectively.

\subsection{Vegetation Indices Based on UAS Remote Sensing in the} Visible Spectra Region. UAS remote sensing is a low altitude remote sensing technology $(50-100 \mathrm{~m})$, which is less affected by atmospheric factors during the data acquisition process. It has the advantages of affordability, simple operation, fast imaging speed, and high spatial and temporal resolutions, which is unparalleled compared with traditional [58] remote sensing technologies based on satellites. At present, the UAS remote sensing technology plays a crucial role in the field of aerial remote sensing with increased interest in applying these platforms on different studies of vegetation assessment [59]. The practical applications of UAS are mainly related to images acquisition in the visible bands (RGB) due to easy access of ubiquitous high resolution cameras at low price and weight. However, due to rapid advances in technology, multispectral and infrared thermal cameras are becoming increasingly cheaper and miniaturized.

As previously shown through different VIs, most of them are based on the mixture of visible light bands and NIR to generate algorithms and those based only on the visible light spectra are not common. However, weightless high definition cameras are appearing in the market that includes the NIR band, which will enhance the practical applicability of UAS in the near future. These types of reflectance are commonly measured using visible, multispectral, and hyperspectral cameras [5]. According to Gago et al. (2015), NDVI is one of the most employed indices for UAS applications and is defined specifically as

$$
\mathrm{NDVI}=\frac{\left(R_{800}-R_{680}\right)}{\left(R_{800}+R_{680}\right)},
$$

where $R_{800}$ is the reflectance at $800 \mathrm{~nm}$ and $R_{680}$ at $680 \mathrm{~nm}$. Due to the high NIR reflectance of chlorophyll, this index is used to detect plants greenness [60]. Some studies described the use of UAS with multispectral cameras and high resolution multispectral satellites to estimate LAI (Leaf Area Index) through NDVI $[27,61]$.

The optimized index transformed chlorophyll absorption in reflectance Transformed Chlorophyll Absorption in Reflectance Index/Optimized Soil-Adjusted Vegetation Index (TCARI/OSAVI) was proposed as more sensitive VI to chlorophyll content. In this way, avoiding other factors that could affect the reflectance values such as canopy reflectance and soil reflectance among others [5]. Another index evaluated by Zarco-Tejada et al. (2013) was the PRInorm, which is an improvement of the Photochemical Reflectance Index (PRI). This index considers xanthophyll changes related to water stress but also generates a normalization considering chlorophyll content and canopy leaf area reduction which is mainly affected by water stress [62]. However, by obtaining a quick and effective method to extract vegetation information based on UAS visible images, it will enhance and popularize the scope of application of UAS immediately [63]. In this sense, Wang et al. (2015) comprehensively considered the spectral characteristics of healthy green vegetation and the spectral characteristics of typical features of UAS imagery [63]. They use green $(G)$ band instead of the NIR band to calculate NDVI, $\left(\rho_{\text {red }}+\rho_{\text {blue }}\right)$ compared to $R$ for NDVI, and the $G$ band multiplied by 2 for $\left(\rho_{\text {red }}+\rho_{\text {blue }}\right)$. Thus, a Visible-Band Difference Vegetation Index (VDVI) is created based on the three bands of visible light, which can be expressed as follows:

$$
\operatorname{VDVI}=\frac{\left(2 * \rho_{\text {green }}-\rho_{\text {red }}-\rho_{\text {blue }}\right)}{\left(2 * \rho_{\text {green }}+\rho_{\text {red }}+\rho_{\text {blue }}\right)}
$$

The values of VDVI are within $[-1,1]$ and the accuracy of the vegetation extraction based on VDVI is higher than other visible light band-based VIs and $G$ band. Furthermore, the accuracy of VDVI has been reported to be over 90\% [63].

2.6. Vegetation Indices Related to Vegetation Status. The NDVI, as shown previously, enhances the contrast of the reflectivity of the NIR and $R$ channels (5). Therefore, it is a nonlinear extension of NIR and $R$ ratios, resulting in the enhancement of the lower part of these values (higher values are suppressed). Hence, NDVI reaches saturation in this way more easily. Thus, Gitelson [64] proposed the Wide Dynamic Range Vegetation Index (WDRVI), which can be expressed as follows:

$$
\text { WDRVI }=\frac{\left(\alpha \rho_{\text {nir }}-\rho_{\text {red }}\right)}{\left(\alpha \rho_{\text {nir }}+\rho_{\text {red }}\right)}
$$

WDRVI enhances the dynamic range of NDVI by applying a weighting parameter to the NIR reflectance. If $\alpha$ equals 1 , WDRVI is equivalent to NDVI. If $\alpha$ is equal to the ratio $\left(\rho_{\text {red }} / \rho_{\text {NIR }}\right)$, WDRVI is zero. After validation procedures, a coefficient value of 0.20 for appears to be generally effective for the WDRVI calculations. According to Gitelson (2004) [64], WDRVI offers a simple way to enhance the dynamic range for high biomass environments (LAI > 2). However, when biomass is low (LAI $<1)$, NDVI is still the best choice for the plant classification.

According to the spectral reflectance of plant leaves (between $550 \mathrm{~nm}$ and $700 \mathrm{~nm}$ ) it can be considered constant even if the chlorophyll content of leaves is variable. Based on this relationship, Kim et al. (1994) measured the level of absorption at $670 \mathrm{~nm}$ and linked the reflection peak at $700 \mathrm{~nm}$ 
and $550 \mathrm{~nm}$; the Chlorophyll Absorption Ratio Index (CARI) was then developed [65] and can be expressed as

$$
\begin{gathered}
\operatorname{CAR} *\left(\frac{R_{700}}{R_{670}}\right), \\
\operatorname{CAR}=\frac{\left|\left(a * 670+R_{670}+b\right)\right|}{\left(a^{2}+1\right)^{0.5},} \\
a=\frac{\left(R_{700}-R_{500}\right)}{150}, \\
b=R_{550}-(a * 550) .
\end{gathered}
$$

Later, Daughtry et al. improved the CARI by proposing a modified CARI (MCARI) [66], which can be expressed as

$$
\begin{aligned}
& \text { MCARI } \\
& \qquad \frac{1.5 *\left[2.5\left(R_{800}-R_{670}\right)-1.3\left(R_{800}-R_{550}\right)\right]}{\sqrt{\left(2 R_{800}+1\right)^{2}-\left(6 R_{800}-5 R_{670}\right)-0.5}} .
\end{aligned}
$$

The MCARI is more sensitive to leaf chlorophyll concentrations. Daughtry et al. (2000) found that LAI, chlorophyll, and the chlorophyll-LAI interaction accounted for 60, 27, and $13 \%$ of the MCARI variation. Even though the MCARI formula is not related to the NIR bands, good predictions were still found.

In agriculture, crop growth is directly linked to water supply and plant water status. When the soil water supply is insufficient, plants will be under water stress, which leads to reduced crop yield and even crop failures under extreme drought conditions. So it is very important to evaluate the crop water status in a timely and accurate manner, which has direct implications on crop growth, yield, and quality of produce [67]. In recent years, the development of infrared thermal remote sensing technology made it possible to measure canopy temperature changes and dynamics from crop populations. These changes are related to the transpiration rate of plants and stomatal conductance. Hence, crop leaf and canopy temperature have been used for the determination of crop water status [68]. In order to make the canopy temperature measurements consistent, Idso et al. (1981) established the Crop Water Stress Index (CWSI) to monitor crop water status [69].

$$
\text { CWSI }=\frac{\left(T_{\text {canopy }}-T_{\text {nws }}\right)}{\left(T_{\text {dry }}-T_{\text {nws }}\right)},
$$

where $T_{\text {canopy }}$ is the temperature of fully sunlit canopy leaves $\left({ }^{\circ} \mathrm{C}\right), T_{\text {nws }}$ is the temperature of fully sunlit canopy leaves $\left({ }^{\circ} \mathrm{C}\right)$ when the crop is non-water-stressed (well-watered); $T_{\text {dry }}$ is the temperature of fully sunlit canopy leaves $\left({ }^{\circ} \mathrm{C}\right)$ when the crop is severely water stressed due to low soil water availability. $T_{\text {nws }}$ and $T_{\text {dry }}$ are the lower and upper baselines used to normalize CWSI for the effects of environmental conditions (air temperature, relative humidity, solar radiation, and wind speed) on $T_{\text {canopy }}$. The CWSI has two models, an empirical model and a theoretical model; however, the theoretical model involves too many parameters, and these parameters are not easy to obtain. Therefore, the theoretical model is only used for research purposes [70-72]. The empirical model can be obtained only by using crop canopy temperature, air temperature, and air saturation difference, so the empirical model has been further studied and used in many crop applications [73].

Besides the use of infrared thermal radiation to detect plant water stress detection, the visible part of the spectrum has also been useful for early water stress detection. This involves using indices focused on bands at specific wavelengths where photosynthetic pigments are affected by water stress conditions such as chlorophyll. The Photochemical Reflectance Index (PRI) has been used as a stress index of stress based on this principle, with initial developments to be applied to disease symptoms detection, which can be expressed as

$$
\text { PRI }=\frac{\left(R_{531}-R_{570}\right)}{\left(R_{531}-R_{570}\right)} .
$$

It has been shown that the Light Use Efficiency (LUE) is a key variable to estimate Net Primary Productivity (NPP) [74, 75]. When obtaining reliable accuracy in LUE measurements, it is possible to study the distribution of energy and global climate change. The PRI is a normalized difference VI of reflectivity at $531 \mathrm{~nm}$ and $570 \mathrm{~nm}$ and the reflectance of these two bands is affected by the xanthophyll cycle and is closely related to LUE of leaves. Therefore, PRI provides a good estimation of leaf LUE.

2.7. Summary of Vegetation Indices. A summary of the main VIs discussed in this paper can be found in Table 1 with their respective citations.

\section{Conclusions}

Simple VIs combining visible and NIR bands have significantly improved the sensitivity of the detection of green vegetation. Different environments have their own variable and complex characteristics, which needs to be accounted when using different VIs. Therefore, each VI has its specific expression of green vegetation, its own suitability for specific uses, and some limiting factors. Therefore, for practical applications, the choice of a specific VI needs to be made with caution by comprehensively considering and analyzing the advantages and limitations of existing VIs and then combine them to be applied in a specific environment. In this way, the usage of VIs can be tailored to specific applications, instrumentation used, and platforms. With the development of hyperspectral and multispectral remote sensing technology, new VIs can be developed, which will broaden research areas. It is envisioned that these new developments will be readily applied and adopted by UAS platforms and will become one of the most important research areas in aerospace remote sensing in the near future. 
TABLE 1: Summary of vegetation index expression.

\begin{tabular}{|c|c|c|}
\hline Index & Definition & Reference \\
\hline AGVI & $\mathrm{GVI}-(1+0.018 \mathrm{GVI}) * \mathrm{YVI}-\frac{\mathrm{NSI}}{2}$ & {$[76]$} \\
\hline ARI & $\left(\frac{1}{R_{550}}\right)-\left(\frac{1}{R_{700}}\right)$ & {$[76]$} \\
\hline ARI2 & $R_{800}\left[\left(\frac{1}{R_{550}}\right)-\left(\frac{1}{R_{700}}\right)\right]$ & {$[76]$} \\
\hline ARVI & $\frac{(\mathrm{NIR}-R B)}{(\mathrm{NIR}+R B)}$ & {$[40]$} \\
\hline ASBI & $0.2 \mathrm{YVI}$ & [77] \\
\hline ATSAVI & $\frac{[a(\mathrm{NIR}-a \operatorname{Red}-b)]}{\left[a \mathrm{NIR}+\operatorname{Red}-a b+X\left(1+a^{2}\right)\right]}$ & {$[78]$} \\
\hline AVI & $2.0 \mathrm{MSS}_{7}-\mathrm{MSS}_{5}$ & {$[79]$} \\
\hline AVI & $\tan ^{-1}\left\{\left[\frac{\left(\lambda_{3}-\lambda_{2}\right)}{\lambda_{2}}\right](\mathrm{NIR}-R)^{-1}\right\}+\tan ^{-1}\left\{\left[\frac{\left(\lambda_{2}-\lambda_{1}\right)}{\lambda_{2}}\right](G-R)^{-1}\right\}$ & {$[80]$} \\
\hline BGI1 & $\frac{R_{400}}{R_{550}}$ & {$[81]$} \\
\hline BGI2 & $\frac{R_{450}}{R_{550}}$ & [81] \\
\hline BRI1 & $\frac{R_{400}}{R_{690}}$ & {$[60]$} \\
\hline BRI2 & $\frac{R_{450}}{R_{690}}$ & {$[60]$} \\
\hline CAI & $0.5\left(R_{2000}+R_{2200}\right)-R_{2100}$ & [82] \\
\hline CARI & $\mathrm{CAR} *\left(\frac{R_{700}}{R_{670}}\right)$ & {$[65]$} \\
\hline CCCI & $\frac{\left(\mathrm{NDRE}-\mathrm{NDRE}_{\min }\right)}{\left(\mathrm{NDRE}_{\max }-\mathrm{NDRE}_{\min }\right)}$ & {$[83]$} \\
\hline CRCWD & $1-\rho_{\min }^{r}$ & {$[84]$} \\
\hline CRI500 & $\frac{\left(1 / R_{515}\right)}{\left(1 / R_{550}\right)}$ & {$[85]$} \\
\hline CRI700 & $\frac{\left(1 / R_{515}\right)}{\left(1 / R_{700}\right)}$ & [85] \\
\hline CWSI & $\frac{\left(\left(T_{c}-T_{a}\right)-\left(T_{c}-T_{a}\right)_{l l}\right)}{\left(\left(T_{c}-T_{a}\right)_{u l}-\left(T_{c}-T_{a}\right)_{l l}\right)}$ & [69] \\
\hline DI1 & $R_{800}-R_{550}$ & {$[86]$} \\
\hline DVI & $\int_{\lambda_{1}}^{\lambda_{1}}\left(\frac{d_{\rho}}{d_{\lambda}}\right) d \lambda$ & {$[87]$} \\
\hline DVI & $2.4 \mathrm{MSS}_{7}-\mathrm{MSS}_{5}$ & {$[38]$} \\
\hline EVI & $\frac{\left[\left(\mathrm{TM}_{4}-\mathrm{TM}_{3}\right)(1+L)\right]}{\left(\mathrm{TM}_{4}-C_{1} \mathrm{TM}_{3}+C_{2} \mathrm{TM}+L\right)}$ & {$[88]$} \\
\hline EXG & $2 * \rho_{\text {green }}-\rho_{\text {red }}-\rho_{\text {blue }}$ & {$[89,90]$} \\
\hline GARI & $\frac{\{\text { NIR }-[\text { Green }-\gamma(\text { Blue }- \text { Red })]\}}{\{\text { NIR }+[\text { Green }-\gamma(\text { Blue }- \text { Red })]\}}$ & [24] \\
\hline GDVI & NIR - Green & {$[23]$} \\
\hline
\end{tabular}


TABLe 1: Continued.

\begin{tabular}{|c|c|c|}
\hline Index & Definition & Reference \\
\hline GEMI & $\begin{array}{c}\eta(1-0.25 \eta)-\frac{(R-0.125)}{(1-R)} \\
\eta=\frac{\left[2\left(\mathrm{NIR}^{2}-R^{2}\right)+1.5 \mathrm{NIR}+0.5 R\right]}{(\mathrm{NIR}+R+0.5)}\end{array}$ & {$[90]$} \\
\hline GLI & $\frac{\left(2 R_{g}-R_{r}-R_{b}\right)}{\left(2 R_{g}+R_{r}+R_{b}\right)}$ & {$[91]$} \\
\hline GM1 & $\frac{R_{750}}{R_{550}}$ & {$[92]$} \\
\hline GM2 & $\frac{R_{750}}{R_{700}}$ & {$[92]$} \\
\hline GNDVI & $\frac{\left(\rho_{\mathrm{NIR}}-\rho_{\mathrm{G}}\right)}{\left(\rho_{\mathrm{NIR}}+\rho_{G}\right)}$ & [91] \\
\hline GRABS & GVI $-0.09178 \mathrm{SBI}+5.58959$ & {$[93]$} \\
\hline GRVI & $\frac{\text { NIR }}{\text { Green }}$ & {$[23]$} \\
\hline Greenness index $(G)$ & $\frac{R_{554}}{R_{677}}$ & {$[94]$} \\
\hline GVI & $\left(-0.283 \mathrm{MSS}_{4}-0.66 \mathrm{MSS}_{5}+0.577 \mathrm{MSS}_{6}+0.388 \mathrm{MSS}_{7}\right)$ & {$[53]$} \\
\hline GVSB & $\frac{\mathrm{GVI}}{\mathrm{SBI}}$ & {$[95]$} \\
\hline LIC3 & $\frac{R_{400}}{R_{740}}$ & {$[96]$} \\
\hline HJVI & $\frac{\left[2\left(\rho_{\text {nir }}-\rho_{\text {red }}\right)\right]}{\left(\rho_{\text {nir }}+6 \rho_{\text {red }}-7.5 \rho_{\text {blue }}+1\right)}$ & {$[97]$} \\
\hline $\mathrm{HI}$ & $\frac{\left(R_{534}-R_{698}\right)}{\left(R_{534}+R_{698}\right)}-0.5 R_{704}$ & {$[98]$} \\
\hline IAVI & $\frac{\left\{\rho_{\text {nir }}-\left[\rho_{r}-\gamma\left(\rho_{b}-\rho_{r}\right)\right]\right\}}{\left\{\rho_{\text {nir }}+\left[\rho_{r}-\gamma\left(\rho_{b}-\rho_{r}\right)\right]\right\}}$ & {$[46]$} \\
\hline II & $\frac{\mathrm{TM}_{5}}{\mathrm{TM}_{7}}$ & [99] \\
\hline IPVI & $\frac{\mathrm{TM}_{4}}{\left(\mathrm{TM}_{4}+\mathrm{TM}_{3}\right)}$ & {$[100]$} \\
\hline MCARI & {$\left[\left(R_{700}-R_{670}\right)-0.2\left(R_{700}-R_{550}\right)\right]\left(\frac{R_{700}}{R_{670}}\right)$} & {$[66]$} \\
\hline MCARI & $\frac{1.5 *\left[2.5\left(R_{800}-R_{670}\right)-1.3\left(R_{800}-R_{550}\right)\right]}{\sqrt{\left(2 R_{800}+1\right)^{2}-\left(6 R_{800}-5 R_{670}\right)-0.5}}$ & [101] \\
\hline MGVI & $\left(-0.386 \mathrm{MSS}_{4}-0.53 \mathrm{MSS}_{5}+0.535 \mathrm{MSS}_{6}+0.532 \mathrm{MSS}_{7}\right)$ & {$[102]$} \\
\hline MNLI & $\frac{\left[\left(\mathrm{NIR}^{2}-\mathrm{Red}\right)(1+L)\right]}{\left(\mathrm{NIR}^{2}+\operatorname{Red}+L\right)}$ & {$[103]$} \\
\hline MNSI & $\left(0.404 \mathrm{MSS}_{4}-0.039 \mathrm{MSS}_{5}-0.505 \mathrm{MSS}_{6}+0.762 \mathrm{MSS}_{7}\right)$ & {$[102]$} \\
\hline MRENDVI & $\frac{\left(\rho_{750}-\rho_{705}\right)}{\left(\rho_{750}+\rho_{705}-2 * \rho_{445}\right)}$ & {$[104,105]$} \\
\hline
\end{tabular}


TABle 1: Continued.

\begin{tabular}{|c|c|c|}
\hline Index & Definition & Reference \\
\hline MRESR & $\frac{\left(\rho_{750}-\rho_{445}\right)}{\left(\rho_{705}-\rho_{445}\right)}$ & {$[104,105]$} \\
\hline MSAVI2 & $0.5 *\left[(2 \mathrm{NIR}+1)-\sqrt{(2 \mathrm{NIR}+1)^{2}-8(\mathrm{NIR}-R)}\right]$ & [106] \\
\hline MSBI & $\left(0.406 \mathrm{MSS}_{4}+0.60 \mathrm{MSS}_{5}+0.645 \mathrm{MSS}_{6}+0.243 \mathrm{MSS}_{7}\right)$ & {$[102]$} \\
\hline MSAVI & $0.5 *\left\{2 R_{800}+1-\operatorname{SQRT}\left[\left(2 R_{800}+1\right)^{2}-8\left(R_{800}-R_{670}\right)\right]\right\}$ & {$[51]$} \\
\hline MSR & $\frac{\left[\left(R_{800} / R_{670}\right)-1\right]}{\left[\operatorname{SQRT}\left(R_{800} / R_{670}+1\right)\right]}$ & [106] \\
\hline MSI & $\frac{\rho_{1599}}{\rho_{819}}$ & [107] \\
\hline MTVI & $1.2 *\left[1.2\left(R_{800}-R_{550}\right)-2.5\left(R_{670}-R_{550}\right)\right]$ & [101] \\
\hline MTVI2 & $\frac{1.5 *\left[1.2\left(R_{800}-R_{550}\right)-2.5\left(R_{670}-R_{550}\right)\right]}{\sqrt{\left(2 * R_{800}+1\right)^{2}-\left(6 * R_{800}-5 * \sqrt{R_{670}}\right)-0.5}}$ & [101] \\
\hline MYVI & $\left(0.723 \mathrm{MSS}_{4}-0.597 \mathrm{MSS}_{5}+0.206 \mathrm{MSS}_{6}-0.278 \mathrm{MSS}_{7}\right)$ & [102] \\
\hline NDGI & $\frac{(G-R)}{(G+R)}$ & [78] \\
\hline NDI & $\frac{(\mathrm{NIR}-\mathrm{MIR})}{(\mathrm{NIR}+\mathrm{MIR})}$ & [108] \\
\hline NDI1 & $\frac{\left(R_{780}-R_{710}\right)}{\left(R_{780}-R_{680}\right)}$ & [109] \\
\hline NDI2 & $\frac{\left(R_{850}-R_{710}\right)}{\left(R_{850}-R_{680}\right)}$ & [109] \\
\hline NDI3 & $\frac{\left(R_{734}-R_{747}\right)}{\left(R_{715}-R_{726}\right)}$ & [110] \\
\hline NDNI & $\frac{\left[\log \left(1 / \rho_{1510}\right)-\log \left(1 / \rho_{1680}\right)\right]}{\left[\log \left(1 / \rho_{1510}\right)+\log \left(1 / \rho_{1680}\right)\right]}$ & [111] \\
\hline NDLI & $\frac{\left[\log \left(1 / \rho_{1754}\right)-\log \left(1 / \rho_{1680}\right)\right]}{\left[\log \left(1 / \rho_{1754}\right)+\log \left(1 / \rho_{1680}\right)\right]}$ & [111] \\
\hline NDVI & $\frac{\left(R_{800}-R_{680}\right)}{\left(R_{800}+R_{680}\right)}$ & [96] \\
\hline NDVI & $\frac{\left(\rho_{\mathrm{NIR}}-\rho_{R}\right)}{\left(\rho_{\mathrm{NIR}}+\rho_{R}\right)}$ & {$[42]$} \\
\hline NDWI & $\frac{(\text { Green }- \text { NIR })}{(\text { Green }+ \text { NIR })}$ & [112] \\
\hline NGBDI & $\frac{(G-R)}{(G+B)}$ & [113] \\
\hline NGRDI & $\frac{(G-R)}{(G+R)}$ & [114] \\
\hline NMDI & $\frac{\left[\rho_{860}-\left(\rho_{1640}-\rho_{2130}\right)\right]}{\left[\rho_{860}+\left(\rho_{1640}-\rho_{2130}\right)\right]}$ & [115] \\
\hline NLI & $\frac{\left(\mathrm{NIR}^{2}-\mathrm{Red}\right)}{\left(\mathrm{NIR}^{2}+\mathrm{Red}\right)}$ & [116] \\
\hline
\end{tabular}


TABLe 1: Continued.

\begin{tabular}{|c|c|c|}
\hline Index & Definition & Reference \\
\hline OSAVI & $\frac{(1+0.16)\left(R_{800}-R_{670}\right)}{\left(R_{800}+R_{670}+0.61\right)}$ & [117] \\
\hline PRI & $\frac{\left(R_{531}-R_{570}\right)}{\left(R_{531}+R_{570}\right)}$ & [118] \\
\hline PSRI & $\frac{\left(R_{680}-R_{500}\right)}{R_{750}}$ & [119] \\
\hline PSNDc & $\frac{\left(R_{800}-R_{470}\right)}{\left(R_{800}+R_{470}\right)}$ & [120] \\
\hline PSSRa & $\frac{R_{800}}{R_{680}}$ & {$[120]$} \\
\hline PSSRb & $\frac{R_{800}}{R_{635}}$ & [120] \\
\hline PSSRc & $\frac{R_{800}}{R_{470}}$ & [120] \\
\hline PVI & $\sqrt{\left(\rho_{\text {soil }}-\rho_{\text {veg }}\right)_{R}^{2}-\left(\rho_{\text {soil }}-\rho_{\text {veg }}\right)_{\text {NIR }}^{2}}$ & {$[38]$} \\
\hline PVI & $\frac{(\mathrm{NIR}-a R-b)}{\sqrt{a^{2}+1}}$ & [121] \\
\hline RARS & $\frac{R_{746}}{R_{513}}$ & [85] \\
\hline RDVI & $\frac{\left(R_{800}-R_{670}\right)}{\left[\operatorname{SQRT}\left(R_{800}+R_{670}\right)\right]}$ & [121] \\
\hline RDVI & $\sqrt{\mathrm{NDIVI} \cdot \mathrm{DVI}}$ & [121] \\
\hline RENDVI & $\frac{\left(R_{750}-R_{705}\right)}{\left(R_{750}+R_{705}\right)}$ & [122] \\
\hline RGRI & $\frac{\left(\sum_{I=600}^{690} R_{I}\right)}{\left(\sum_{I=500}^{599} R_{J}\right)}$ & [123] \\
\hline RI & $\frac{(R-G)}{(R+G)}$ & [124] \\
\hline RVI & $\frac{R}{\mathrm{NIR}}$ & [125] \\
\hline SAVI & $\frac{\left(\rho_{\mathrm{NIR}}-\rho_{\mathrm{G}}\right)}{\left(\rho_{\mathrm{NIR}}+\rho_{\mathrm{G}}+L\right)}+(1+L)$ & [50] \\
\hline SIPI & $\frac{\left(R_{800}-R_{445}\right)}{\left(R_{800}+R_{680}\right)}$ & [126] \\
\hline SBI & $\left(-0.283 \mathrm{MSS}_{4}-0.66 \mathrm{MSS}_{5}+0.577 \mathrm{MSS}_{6}+0.388 \mathrm{MSS}_{7}\right)$ & {$[53]$} \\
\hline SBL & $\mathrm{MSS}_{7}-2.4 \mathrm{MSS}_{5}$ & [38] \\
\hline SDr & $\sum_{N} \rho^{\prime}\left(\lambda_{i}\right)$ & {$[127]$} \\
\hline SGI & $\frac{\mathrm{NIR}}{\operatorname{Red}}$ & [128] \\
\hline SR & $\frac{R_{800}}{R_{670}}$ & {$[36]$} \\
\hline SR2 & $\frac{R_{800}}{R_{550}}$ & [86] \\
\hline
\end{tabular}


TABle 1: Continued.

\begin{tabular}{|c|c|c|}
\hline Index & Definition & Reference \\
\hline SR3 & $\frac{R_{700}}{R_{670}}$ & [129] \\
\hline SR4 & $\frac{R_{740}}{R_{720}}$ & [110] \\
\hline SR5 & $\frac{R_{675}}{\left(R_{700} R_{650}\right)}$ & [130] \\
\hline SR6 & $\frac{R_{672}}{\left(R_{550} R_{708}\right)}$ & [126] \\
\hline SR7 & $\frac{R_{860}}{\left(R_{550} R_{708}\right)}$ & [131] \\
\hline TCARI & $3 *\left[\left(R_{700}-R_{670}\right)-0.2 *\left(R_{700}-R_{550}\right)\left(\frac{R_{700}}{R_{670}}\right)\right]$ & [126] \\
\hline TDVI & $\sqrt{0.5+\left[\frac{(\mathrm{NIR}-\mathrm{Red})}{(\mathrm{NIR}+\mathrm{Red})}\right]}$ & {$[132]$} \\
\hline TSARVI & $\frac{\left[a_{r b}\left(\mathrm{NIR}-a_{r b} R B-b_{r b}\right)\right]}{\left[R B+a_{r b} \mathrm{NIR}-a_{r b} b_{r b}+X\left(1+a_{r b}^{2}\right)\right]}$ & [49] \\
\hline TSAVI & $\frac{[a(\mathrm{NIR}-a R-B)]}{[R+a \mathrm{NIR}-a b]}$ & [133] \\
\hline TVI & $\sqrt{\mathrm{NDVI}+0.5 L}$ & [134] \\
\hline VARI & $(G-R)(G+R-B)$ & [135] \\
\hline VCI & $\frac{\left(\mathrm{NDVI}_{i}-\mathrm{NDVI}_{\min }\right)}{\left(\mathrm{NDVI}_{\max }-\mathrm{NDVI}_{\min }\right)}$ & [136] \\
\hline VDVI & $\frac{\left(2 * \rho_{\text {green }}-\rho_{\text {red }}-\rho_{\text {blue }}\right)}{\left(2 * \rho_{\text {green }}+\rho_{\text {red }}+\rho_{\text {blue }}\right)}$ & {$[63]$} \\
\hline VHI & $a * \mathrm{VCI}+(1-a) * \mathrm{TCI}$ & [136] \\
\hline VREI1 & $\frac{R_{740}}{R_{720}}$ & {$[110]$} \\
\hline VREI2 & $\frac{\left(R_{734}-R_{747}\right)}{\left(R_{715}+R_{726}\right)}$ & [110] \\
\hline YVI & $\left(-0.283 \mathrm{MSS}_{4}-0.66 \mathrm{MSS}_{5}+0.577 \mathrm{MSS}_{6}+0.388 \mathrm{MSS}_{7}\right)$ & {$[53]$} \\
\hline WBI & $\frac{R_{970}}{R_{900}}$ & [115] \\
\hline WDRVI & $\frac{\left(\alpha \rho_{\text {nir }}-\rho_{\text {red }}\right)}{\left(\alpha \rho_{\text {nir }}+\rho_{\text {red }}\right)}$ & {$[64]$} \\
\hline WV-VI & $\frac{(\mathrm{NIR} 2-\mathrm{Red})}{(\mathrm{NIR} 2+\mathrm{Red})}$ & {$[137]$} \\
\hline $\mathrm{ZM}$ & $\frac{R_{750}}{R_{710}}$ & {$[81]$} \\
\hline 1DZ -DGVI & $\sum_{\lambda_{1}}^{\lambda_{n}}\left|\rho^{\prime}\left(\lambda_{i}\right)\right| \Delta \lambda_{i}$ & [138] \\
\hline 2DZ -DGVI & $\sum_{\lambda_{1}}^{\lambda_{n}}\left|\rho^{\prime \prime}\left(\lambda_{i}\right)\right| \Delta \lambda_{i}$ & {$[138]$} \\
\hline
\end{tabular}




\section{Conflicts of Interest}

The authors declare that they have no conflicts of interest.

\section{Acknowledgments}

This study was supported by the National Natural Science Foundation of China (no. 41401391); Key Science and Technology Program of Shaanxi Province, China (no. S2016YFNY0066); the Scientific Research Foundation for the Returned Overseas Chinese Scholars, State Education Ministry; the National Key Research and Development Program of China (no. 2016YFD0200601); the Fundamental Research Funds for the Central Universities of China (no. 2014YB071); and the Exclusive Talent Funds of Northwest A\&F University of China (no. 2013BSJJ017).

\section{References}

[1] D. J. Mulla, "Twenty five years of remote sensing in precision agriculture: key advances and remaining knowledge gaps," Biosystems Engineering, vol. 114, no. 4, pp. 358-371, 2013.

[2] W. J. Foley, A. McIlwee, I. Lawler, L. Aragones, A. P. Woolnough, and N. Berding, "Ecological applications of near infrared reflectance spectroscopy - A tool for rapid, cost-effective prediction of the composition of plant and animal tissues and aspects of animal performance," Oecologia, vol. 116, no. 3, pp. 293-305, 1998.

[3] C. Zhang and J. M. Kovacs, "The application of small unmanned aerial systems for precision agriculture: a review," Precision Agriculture, vol. 13, no. 6, pp. 693-712, 2012.

[4] R. Ballesteros, J. F. Ortega, D. Hernández, and M. Moreno, "Characterization of vitis vinifera l. Canopy using unmanned aerial vehicle-based remote sensing and photogrammetry techniques," American Journal of Enology and Viticulture, vol. 66, no. 2, pp. 120-129, 2015.

[5] J. Gago, C. Douthe, R. E. Coopman et al., "UAVs challenge to assess water stress for sustainable agriculture," Agricultural Water Management, vol. 153, pp. 9-19, 2015.

[6] H. Hoffmann, H. Nieto, R. Jensen, R. Guzinski, P. J. ZarcoTejada, and T. Friborg, "Estimating evapotranspiration with thermal UAV data and two source energy balance models," Hydrology and Earth System Sciences Discussions, vol. 12, no. 8, pp. 7469-7502, 2015.

[7] E. Honkavaara, H. Saari, J. Kaivosoja et al., "Processing and assessment of spectrometric, stereoscopic imagery collected using a lightweight UAV spectral camera for precision agriculture," Remote Sensing, vol. 5, no. 10, pp. 5006-5039, 2013.

[8] T. Xia, W. P. Kustas, M. C. Anderson et al., "Mapping evapotranspiration with high-resolution aircraft imagery over vineyards using one-and two-source modeling schemes," Hydrology and Earth System Sciences, vol. 20, no. 4, pp. 1523-1545, 2016.

[9] S. Ortega-Farías, S. Ortega-Salazar, T. Poblete et al., "Estimation of energy balance components over a drip-irrigated olive orchard using thermal and multispectral cameras placed on a helicopter-based unmanned aerial vehicle (UAV)," Remote Sensing, vol. 8, no. 8, article no. 638, 2016.

[10] L. Chang, S. Peng-Sen, and Liu Shi-Rong, "A review of plant spectral reflectance response to water physiological changes," Chinese Journal of Plant Ecology, vol. 40, no. 1, pp. 80-91, 2016.
[11] H. R. Bin Abdul Rahim, M. Q. Bin Lokman, S. W. Harun et al., "Applied light-side coupling with optimized spiral-patterned zinc oxide nanorod coatings for multiple optical channel alcohol vapor sensing," Journal of Nanophotonics, vol. 10, no. 3, Article ID 036009, 2016.

[12] B. A. Cruden, D. Prabhu, and R. Martinez, "Absolute radiation measurement in venus and mars entry conditions," Journal of Spacecraft and Rockets, vol. 49, no. 6, pp. 1069-1079, 2012.

[13] J. Hatfield, J. Baker, and T. J. Arkebauer, "Leaf radiative properties and the leaf energy budget," in Micrometeorology in Agricultural Systems, Agronomy Monograph, American Society of Agronomy, Crop Science Society of America, and Soil Science Society of America, Madison, Wis, USA, 2005.

[14] G. D. Batten, "Plant analysis using near infrared reflectance spectroscopy: The potential and the limitations," Australian Journal of Experimental Agriculture, vol. 38, no. 7, pp. 697-706, 1998.

[15] D. A. Burns and E. W. Ciurczak, Handbook of Near-Infrared Analysis, CRC Press, 2007.

[16] R. Karwa, "Laws of thermal radiation," in Heat and Mass Transfer, pp. 665-696, Springer, 2017.

[17] A. Prashar and H. G. Jones, "Assessing drought responses using thermal infrared imaging," Methods in Molecular Biology, vol. 1398, pp. 209-219, 2016.

[18] A. Martynenko, K. Shotton, T. Astatkie et al., “Thermal imaging of soybean response to drought stress: the effect of ascophyllum nodosum seaweed extract," SpringerPlus, vol. 5, no. 1, no. 1393, 2016.

[19] S. Fuentes, R. de Bei, J. Pech, and S. Tyerman, "Computational water stress indices obtained from thermal image analysis of grapevine canopies," Irrigation Science, vol. 30, no. 6, pp. $523-$ 536, 2012.

[20] A.-K. Mahlein, E.-C. Oerke, U. Steiner, and H.-W. Dehne, "Recent advances in sensing plant diseases for precision crop protection," European Journal of Plant Pathology, vol. 133, no. 1, pp. 197-209, 2012.

[21] E.-C. Oerke, A.-K. Mahlein, and U. Steiner, "Proximal sensing of plant diseases," in Detection And Diagnostics of Plant Pathogens, pp. 55-68, Springer, 2014.

[22] A. Karnieli, N. Agam, R. T. Pinker et al., "Use of NDVI and land surface temperature for drought assessment: merits and limitations," Journal of Climate, vol. 23, no. 3, pp. 618-633, 2010.

[23] R. P. Sripada, R. W. Heiniger, J. G. White, and R. Weisz, "Aerial color infrared photography for determining late-season nitrogen requirements in corn," Agronomy Journal, vol. 97, no. 5, pp. 1443-1451, 2005.

[24] B. Zhang, D. Wu, L. Zhang, Q. Jiao, and Q. Li, "Application of hyperspectral remote sensing for environment monitoring in mining areas," Environmental Earth Sciences, vol. 65, no. 3, pp. 649-658, 2012.

[25] A. N. Ganeshamurthy, V. Ravindra, R. Venugopalan, M. Mathiazhagan, and R. M. Bhat, "Biomass distribution and development of allometric equations for non-destructive estimation of carbon sequestration in grafted mango trees," Journal of Agricultural Science, vol. 8, no. 8, 201 pages, 2016.

[26] S. Fuentes, A. R. Palmer, D. Taylor, M. Zeppel, R. Whitley, and D. Eamus, "An automated procedure for estimating the leaf area index (LAI) of woodland ecosystems using digital imagery, MATLAB programming and its application to an examination of the relationship between remotely sensed and field measurements of LAI," Functional Plant Biology, vol. 35, no. 10, pp. 1070$1079,2008$. 
[27] S. Fuentes, C. Poblete-Echeverría, S. Ortega-Farias, S. Tyerman, and R. de Bei, "Automated estimation of leaf area index from grapevine canopies using cover photography, video and computational analysis methods," Australian Journal of Grape and Wine Research, vol. 20, no. 3, pp. 465-473, 2014.

[28] C. Poblete-Echeverría, S. Fuentes, S. Ortega-Farias, J. GonzalezTalice, and J. A. Yuri, "Digital cover photography for estimating Leaf area index (LAI) in apple trees using a variable light extinction coefficient," Sensors (Switzerland), vol. 15, no. 2, pp. 2860-2872, 2015.

[29] M. Carrasco-Benavides, S. Ortega-Farías, L. O. Lagos et al., "Crop coefficients and actual evapotranspiration of a dripirrigated Merlot vineyard using multispectral satellite images," Irrigation Science, vol. 30, no. 6, pp. 485-497, 2012.

[30] M. Mora, F. Avila, M. Carrasco-Benavides, G. Maldonado, J. Olguín-Cáceres, and S. Fuentes, "Automated computation of leaf area index from fruit trees using improved image processing algorithms applied to canopy cover digital photograpies," Computers and Electronics in Agriculture, vol. 123, pp. 195-202, 2016.

[31] R. De Bei, S. Fuentes, M. Gilliham et al., "Viticanopy: A free computer app to estimate canopy vigor and porosity for grapevine," Sensors (Switzerland), vol. 16, no. 4, article no. 585, 2016.

[32] S. Fuentes, R. De Bei, C. Pozo, and S. Tyerman, "Development of a smartphone application to characterise temporal and spatial canopy architecture and leaf area index for grapevines," Wine \& Viticulture Journal, vol. 20, no. 6, pp. 56-60, 2012.

[33] C. Francone, V. Pagani, M. Foi, G. Cappelli, and R. Confalonieri, "Comparison of leaf area index estimates by ceptometer and pocketlai smart app in canopies with different structures," Field Crops Research, vol. 155, pp. 38-41, 2014.

[34] F. Orlando, E. Movedi, L. Paleari et al., "Estimating leaf area index in tree species using the PocketLAI smart app," Applied Vegetation Science, vol. 18, no. 4, pp. 716-723, 2015.

[35] M. Campos-Taberner, F. J. García-Haro, R. Confalonieri et al., "Multitemporal monitoring of plant area index in the valencia rice district with PocketLAI," Remote Sensing, vol. 8, no. 3, article no. 202, 2016.

[36] C. F. Jordan, "Derivation of leaf-area index from quality of light on the forest floor," Ecology, vol. 50, no. 4, pp. 663-666, 1969.

[37] Z. Quan, Z. Xianfeng, and J. Miao, "Eco-environment variable estimation from remote sensed data and eco-environment assessment: models and system," Acta Botanica Sinica, vol. 47, pp. 1073-1080, 2011.

[38] A. J. Richardson and C. Weigand, "Distinguishing vegetation from soil background information," Photogrammetric Engineering and Remote Sensing, p. 43, 1977.

[39] X. D. L. Wenlong, "Vegetation index controlling the influence of soil reflection," 2009, http://www.paper.edu.cn/releasepaper/ content/200906-376.

[40] Y. J. Kaufman and D. Tanré, "Atmospherically Resistant Vegetation Index (ARVI) for EOS-MODIS," IEEE Transactions on Geoscience and Remote Sensing, vol. 30, no. 2, pp. 261-270, 1992.

[41] D. J. Major, F. Baret, and G. Guyot, "A ratio vegetation index adjusted for soil brightness," International Journal of Remote Sensing, vol. 11, no. 5, pp. 727-740, 1990.

[42] J. W. Rouse Jr., R. Haas, J. Schell, and D. Deering, "Monitoring vegetation systems in the great plains with erts," NASA Special Publication 351, 309, 1974.

[43] J. A. Gamon, C. B. Field, M. L. Goulden et al., "Relationships between NDVI, canopy structure, and photosynthesis in three Californian vegetation types," Ecological Applications, vol. 5, no. 1, pp. 28-41, 1995.
[44] J. Grace, C. Nichol, M. Disney, P. Lewis, T. Quaife, and P. Bowyer, "Can we measure terrestrial photosynthesis from space directly, using spectral reflectance and fluorescence?" Global Change Biology, vol. 13, no. 7, pp. 1484-1497, 2007.

[45] D. Tanré, C. Deroo, P. Duhaut et al., "Description of a computer code to simulate the satellite signal in the solar spectrum: the $5 \mathrm{~S}$ code," International Journal of Remote Sensing, vol. 11, no. 4, pp. 659-668, 1990.

[46] R.-H. Zhang, N. X. Rao, and K. N. Liao, "Approach for a vegetation index resistant to atmospheric effect," Acta Botanica Sinica, vol. 38, no. 1, pp. 53-62, 1996.

[47] A. J. Richardson and C. Wiegand, "Distinguishing vegetation from soil background information," Photogrammetric Engineering \& Remote Sensing, vol. 43, no. 12, pp. 1541-1552, 1977.

[48] F. Baret, S. Jacquemoud, and J. F. Hanocq, "The soil line concept in remote sensing," Remote Sensing Reviews, vol. 7, no. 1, pp. 65$82,1993$.

[49] A. Bannari, D. Morin, and D. He, "High spatial and spectral resolution remote sensing for the management of the urban environment," in Proceedings of the 1st International Airborne Remote Sensing Conference and Exhibition, pp. 12-15, Strasbourg, France, 1994.

[50] A. R. Huete, "A soil-adjusted vegetation index (SAVI)," Remote Sensing of Environment, vol. 25, no. 3, pp. 295-309, 1988.

[51] J. Qi, A. Chehbouni, A. R. Huete, Y. H. Kerr, and S. Sorooshian, "A modified soil adjusted vegetation index," Remote Sensing of Environment, vol. 48, no. 2, pp. 119-126, 1994.

[52] X. Dandan and L. Wenlong, Vegetation Index Controlling The Influence of Soil Reflection, Department of Pastrol Agricultural Science and Technology, 2009.

[53] R. J. Kauth and G. Thomas, "The tasselled cap-a graphic description of the spectral-temporal development of agricultural crops as seen by landsat," in Proceedings of the LARS Symposia, 159 pages, 1976.

[54] T. Qingjiu and M. Xiangjun, "Advances in study on vegetation indices," Department of Pastrol Agricultural Science and Technology, vol. 13, pp. 327-333, 1998.

[55] R. D. Jackson, P. Pinter Jr., R. J. Reginato, and S. B. Idso, "Hand-held radiometry: a set of notes developed for use at the workshop of hand-held radiometry," in Proceedings of the Early Warning and Crop Condition Assessment, Phoenix, Ariz, USA, February 1980.

[56] P. N. Misra and S. G. Wheeler, "Landsat data from agricultural sites: crop signature analysis," pp. 1473-1482, 1977.

[57] H. Q. Liu and A. Huete, "Feedback based modification of the NDVI to minimize canopy background and atmospheric noise," IEEE Transactions on Geoscience and Remote Sensing, vol. 33, no. 2, pp. 457-465, 1995.

[58] L. Wang, J. Liu, L. Yang, Z. Chen, X. Wang, and B. Ouyang, "Applications of unmanned aerial vehicle images on agricultural remote sensing monitoring," Nongye Gongcheng Xuebao/ Transactions of the Chinese Society of Agricultural Engineering, vol. 29, no. 18, pp. 136-145, 2013.

[59] B. Li, R. Liu, S. Liu, Q. Liu, F. Liu, and G. Zhou, "Monitoring vegetation coverage variation of winter wheat by low-altitude UAV remote sensing system," Nongye Gongcheng Xuebao/Transactions of the Chinese Society of Agricultural Engineering, vol. 28, no. 13, pp. 160-165, 2012.

[60] P. J. Zarco-Tejada, V. González-Dugo, and J. A. J. Berni, "Fluorescence, temperature and narrow-band indices acquired from a UAV platform for water stress detection using a micro-hyperspectral imager and a thermal camera," Remote Sensing of Environment, vol. 117, pp. 322-337, 2012. 
[61] J. A. J. Berni, P. J. Zarco-Tejada, G. Sepulcre-Cantó, E. Fereres, and F. Villalobos, "Mapping canopy conductance and CWSI in olive orchards using high resolution thermal remote sensing imagery," Remote Sensing of Environment, vol. 113, no. 11, pp. 2380-2388, 2009.

[62] P. J. Zarco-Tejada, V. González-Dugo, L. E. Williams et al., "A PRI-based water stress index combining structural and chlorophyll effects: Assessment using diurnal narrow-band airborne imagery and the CWSI thermal index," Remote Sensing of Environment, vol. 138, pp. 38-50, 2013.

[63] X. Wang, M. Wang, S. Wang, and Y. Wu, "Extraction of vegetation information from visible unmanned aerial vehicle images," Nongye Gongcheng Xuebao/Transactions of the Chinese Society of Agricultural Engineering, vol. 31, no. 5, pp. 152-159, 2015.

[64] A. A. Gitelson, "Wide dynamic range vegetation index for remote quantification of biophysical characteristics of vegetation," Journal of Plant Physiology, vol. 161, no. 2, pp. 165-173, 2004.

[65] M. S. Kim, C. Daughtry, E. Chappelle, J. McMurtrey, and C. Walthall, "The use of high spectral resolution bands for estimating absorbed photosynthetically active radiation (a par)," in Proceedings of the 6th International Symposium on Physical Measurements and Signatures in Remote Sensing, CNES, Phoenix, Ariz, USA, January 1994.

[66] C. S. T. Daughtry, C. L. Walthall, M. S. Kim, E. B. De Colstoun, and J. E. McMurtrey III, "Estimating corn leaf chlorophyll concentration from leaf and canopy reflectance," Remote Sensing of Environment, vol. 74, no. 2, pp. 229-239, 2000.

[67] Z. Funian, Z. Hong, C. Jiayu, W. Ruijun, and Y. Fuklin, "Preliminary investigation on difference of crop water stress index baseline for maize," Chinese Agricultural Science Bulletin, vol. 29, pp. 46-53, 2013.

[68] S. A. O’Shaughnessy, S. R. Evett, P. D. Colaizzi, and T. A. Howell, "Using radiation thermography and thermometry to evaluate crop water stress in soybean and cotton," Agricultural Water Management, vol. 98, no. 10, pp. 1523-1535, 2011.

[69] S. B. Idso, R. D. Jackson, P. J. Pinter Jr., R. J. Reginato, and J. L. Hatfield, "Normalizing the stress-degree-day parameter for environmental variability," Agricultural Meteorology, vol. 24, pp. 45-55, 1981.

[70] B. B. D. Silva, J. A. Ferreira, and T. V. R. Rao, "Crop water stress index and water-use efficiency for melon (Cucumis melo l.) on different irrigation regimes," Agricultural Journal, 2007.

[71] G. Kar and A. Kumar, "Surface energy fluxes and crop water stress index in groundnut under irrigated ecosystem," Agricultural and Forest Meteorology, vol. 146, no. 1-2, pp. 94-106, 2007.

[72] V. Lebourgeois, J.-L. Chopart, A. Bégué, and L. Le Mézo, "Towards using a thermal infrared index combined with water balance modelling to monitor sugarcane irrigation in a tropical environment," Agricultural Water Management, vol. 97, no. 1, pp. 75-82, 2010.

[73] A. Anda, "Irrigation timing in maize by using the crop water stress index (CWSI)," Cereal Research Communications, vol. 37, no. 4, pp. 603-610, 2009.

[74] A. Ruimy, L. Kergoat, and A. Bondeau, "Comparing global models of terrestrial net primary productivity (NPP): Analysis of differences in light absorption and light-use efficiency," Global Change Biology, vol. 5, no. 1, pp. 56-64, 1999.

[75] A. Haxeltine and I. C. Prentice, "A general model for the lightuse efficiency of primary production," Functional Ecology, vol. 10, no. 5, pp. 551-561, 1996.
[76] A. A. Gitelson, M. N. Merzlyak, and O. B. Chivkunova, "Optical properties and nondestructive estimation of anthocyanin content in plant leaves," Photochemistry and Photobiology, vol. 74, no. 1, pp. 38-45, 2001.

[77] R. D. Jackson, "Spectral indices in N-Space," Remote Sensing of Environment, vol. 13, no. 5, pp. 409-421, 1983.

[78] F. Baret and G. Guyot, "Potentials and limits of vegetation indices for LAI and APAR assessment," Remote Sensing of Environment, vol. 35, no. 2-3, pp. 161-173, 1991.

[79] P. Ashburn, "The vegetative index number and crop identification," NASA, Proc. of Tech., vol. 1, Johnson Space Center, 1979.

[80] S. Plummer, P. North, and S. Briggs, "The angular vegetation index: An atmospherically resistant index for the second along track sacnning radiometer (atsr-2)," in Proceedings of the Sixth International Symposium of Physical Measurements and Signatures in Remote Sensing, Val D'Isere, France, 1994.

[81] P. J. Zarco-Tejada, A. Berjón, R. López-Lozano et al., "Assessing vineyard condition with hyperspectral indices: Leaf and canopy reflectance simulation in a row-structured discontinuous canopy," Remote Sensing of Environment, vol. 99, no. 3, pp. 271-287, 2005.

[82] C. S. T. Daughtry, "Agroclimatology: Discriminating crop residues from soil by shortwave infrared reflectance," Agronomy Journal, vol. 93, no. 1, pp. 125-131, 2001.

[83] F. Li, Y. Miao, G. Feng et al., "Improving estimation of summer maize nitrogen status with red edge-based spectral vegetation indices," Field Crops Research, vol. 157, pp. 111-123, 2014.

[84] N. H. Broge and E. Leblanc, "Comparing prediction power and stability of broadband and hyperspectral vegetation indices for estimation of green leaf area index and canopy chlorophyll density," Remote Sensing of Environment, vol. 76, no. 2, pp. 156$172,2001$.

[85] A. A. Gitelson, G. P. Keydan, and M. N. Merzlyak, “Three-band model for noninvasive estimation of chlorophyll, carotenoids, and anthocyanin contents in higher plant leaves," Geophysical Research Letters, vol. 33, no. 11, Article ID L11402, 2006.

[86] C. Buschmann and E. Nagel, "In vivo spectroscopy and internal optics of leaves as basis for remote sensing of vegetation," International Journal of Remote Sensing, vol. 14, no. 4, pp. 711$722,1993$.

[87] T. H. Demetriades-Shah, M. D. Steven, and J. A. Clark, "High resolution derivative spectra in remote sensing," Remote Sensing of Environment, vol. 33, no. 1, pp. 55-64, 1990.

[88] A. Huete, K. Didan, T. Miura, E. P. Rodriguez, X. Gao, and L. G. Ferreira, "Overview of the radiometric and biophysical performance of the MODIS vegetation indices," Remote Sensing of Environment, vol. 83, no. 1-2, pp. 195-213, 2002.

[89] J. Torres-Sánchez, J. M. Peña, A. I. de Castro, and F. LópezGranados, "Multi-temporal mapping of the vegetation fraction in early-season wheat fields using images from UAV," Computers and Electronics in Agriculture, vol. 103, pp. 104-113, 2014.

[90] B. Pinty and M. M. Verstraete, "GEMI: a non-linear index to monitor global vegetation from satellites," Vegetatio, vol. 101, no. 1, pp. 15-20, 1992.

[91] M. Louhaichi, M. M. Borman, and D. E. Johnson, "Spatially located platform and aerial photography for documentation of grazing impacts on wheat," Geocarto International, vol. 16, no. 1, pp. 65-70, 2001.

[92] A. A. Gitelson and M. N. Merzlyak, "Signature analysis of leaf reflectance spectra: Algorithm development for remote sensing of chlorophyll," Journal of Plant Physiology, vol. 148, no. 3-4, pp. 494-500, 1996. 
[93] E. T. Kanemasu, J. L. Hellman, J. O. Bagley, and W. L. Powers, "Using Landsat data to estimate evapotranspiration of winter wheat," Environmental Management, vol. 1, no. 6, pp. 515-520, 1977.

[94] R. C. G. Smith, J. Adams, D. J. Stephens, and P. T. Hick, "Forecasting wheat yield in a Mediterranean-type environment from the NOAA satellite," Australian Journal of Agricultural Research, vol. 46, no. 1, pp. 113-125, 1995.

[95] G. Badhwar, "The use of parameters to separate and identify spring small grains," in Proceedings of the Quarterly Technical Interchange Meeting NASA Johnson Space Flight Center, Houston, Tex, USA, 1981.

[96] H. K. Lichtenthaler, M. Lang, M. Sowinska, F. Heisel, and J. A. Miehé, "Detection of vegetation stress via a new high resolution fluorescence imaging system," Journal of Plant Physiology, vol. 148, no. 5, pp. 599-612, 1996.

[97] Y. Zhang, Q.-Y. Meng, J.-L. Wu, and F. Zhao, "Study of environmental vegetation index based on environment satellite CCD data and LAI inversion," Guang Pu Xue Yu Guang Pu Fen Xi/ Spectroscopy and Spectral Analysis, vol. 31, no. 10, pp. 2789-2793, 2011.

[98] A.-K. Mahlein, T. Rumpf, P. Welke et al., "Development of spectral indices for detecting and identifying plant diseases," Remote Sensing of Environment, vol. 128, pp. 21-30, 2013.

[99] H. B. Musick and R. E. Pelletier, "Response to soil moisture of spectral indexes derived from bidirectional reflectance in thematic mapper wavebands," Remote Sensing of Environment, vol. 25, no. 2, pp. 167-184, 1988.

[100] R. E. Crippen, "Calculating the vegetation index faster," Remote Sensing of Environment, vol. 34, no. 1, pp. 71-73, 1990.

[101] D. Haboudane, J. R. Miller, E. Pattey, P. J. Zarco-Tejada, and I. B. Strachan, "Hyperspectral vegetation indices and novel algorithms for predicting green LAI of crop canopies: modeling and validation in the context of precision agriculture," Remote Sensing of Environment, vol. 90, no. 3, pp. 337-352, 2004.

[102] P. Misra and S. Wheeler, "Landsat data from agricultural sitescrop signature analysis," in Proceedings of the International Symposium on Remote Sens, pp. 1473-1482, Environ, 1977.

[103] Z. Yang, P. Willis, and R. Mueller, "Impact of band-ratio enhanced awifs image on crop classification accuracy," in Proceedings of the 17th William Pecora Memorial Remote Sensing Symposium, Denver, Colo, USA, 2008.

[104] B. Datt, "A new reflectance index for remote sensing of chlorophyll content in higher plants: Tests using Eucalyptus leaves," Journal of Plant Physiology, vol. 154, no. 1, pp. 30-36, 1999.

[105] D. A. Sims and J. A. Gamon, "Relationships between leaf pigment content and spectral reflectance across a wide range of species, leaf structures and developmental stages," Remote Sensing of Environment, vol. 81, no. 2-3, pp. 337-354, 2002.

[106] J. M. Chen, "Evaluation of vegetation indices and a modified simple ratio for boreal applications," Canadian Journal of Remote Sensing, vol. 22, no. 3, pp. 229-242, 1996.

[107] E. R. Hunt Jr. and B. N. Rock, "Detection of changes in leaf water content using Near- and Middle-Infrared reflectances," Remote Sensing of Environment, vol. 30, no. 1, pp. 43-54, 1989.

[108] H. Mcnairn and R. Protz, "Mapping corn residue cover on agricultural fields in oxford county, ontario, using thematic mapper," Canadian Journal of Remote Sensing, vol. 19, no. 2, pp. 152-159, 1993.

[109] B. Datt, "Visible/near infrared reflectance and chlorophyll content in Eucalyptus leaves," International Journal of Remote Sensing, vol. 20, no. 14, pp. 2741-2759, 1999.
[110] J. E. Vogelmann, B. N. Rock, and D. M. Moss, "Red edge spectral measurements from sugar maple leaves," International Journal of Remote Sensing, vol. 14, no. 8, pp. 1563-1575, 1993.

[111] L. Serrano, J. Peñuelas, and S. L. Ustin, "Remote sensing of nitrogen and lignin in Mediterranean vegetation from AVIRIS data: decomposing biochemical from structural signals," Remote Sensing of Environment, vol. 81, no. 2-3, pp. 355-364, 2002.

[112] S. K. McFeeters, "The use of the Normalized Difference Water Index (NDWI) in the delineation of open water features," International Journal of Remote Sensing, vol. 17, no. 7, pp. 1425-1432, 1996.

[113] J. Verrelst, M. E. Schaepman, B. Koetz, and M. Kneubühler, "Angular sensitivity analysis of vegetation indices derived from CHRIS/PROBA data," Remote Sensing of Environment, vol. 112, no. 5, pp. 2341-2353, 2008.

[114] C. J. Tucker, "Red and photographic infrared linear combinations for monitoring vegetation," Remote Sensing of Environment, vol. 8, no. 2, pp. 127-150, 1979.

[115] L. Wang and J. J. Qu, "NMDI: A normalized multi-band drought index for monitoring soil and vegetation moisture with satellite remote sensing," Geophysical Research Letters, vol. 34, no. 20, Article ID L20405, 2007.

[116] N. S. Goel and W. Qin, "Influences of canopy architecture on relationships between various vegetation indices and LAI and FPAR: a computer simulation," Remote Sensing Reviews, vol. 10, no. 4, pp. 309-347, 1994.

[117] G. Rondeaux, M. Steven, and F. Baret, "Optimization of soiladjusted vegetation indices," Remote Sensing of Environment, vol. 55, no. 2, pp. 95-107, 1996.

[118] J. A. Gamon, J. Peñuelas, and C. B. Field, "A narrow-waveband spectral index that tracks diurnal changes in photosynthetic efficiency," Remote Sensing of Environment, vol. 41, no. 1, pp. 3544, 1992.

[119] M. N. Merzlyak, A. A. Gitelson, O. B. Chivkunova, and V. Y. Rakitin, "Non-destructive optical detection of pigment changes during leaf senescence and fruit ripening," Physiologia Plantarum, vol. 106, no. 1, pp. 135-141, 1999.

[120] G. A. Blackburn, "Quantifying chlorophylls and carotenoids at leaf and canopy scales: An evaluation of some hyperspectral approaches," Remote Sensing of Environment, vol. 66, no. 3, pp. 273-285, 1998.

[121] J.-L. Roujean and F.-M. Breon, "Estimating PAR absorbed by vegetation from bidirectional reflectance measurements," Remote Sensing of Environment, vol. 51, no. 3, pp. 375-384, 1995.

[122] A. Gitelson and M. N. Merzlyak, "Spectral relfectance changes associated with autumn senescence of Aesculus hippocastanum L. and Acer platanoides L. leaves. Spectral features and relation to chlorophyll estimation," Journal of Plant Physiology, vol. 143, no. 3, pp. 286-292, 1994.

[123] J. A. Gamon and J. S. Surfus, "Assessing leaf pigment content and activity with a reflectometer," New Phytologist, vol. 143, no. 1, pp. 105-117, 1999.

[124] R. Escadafal and A. Huete, "Etude des propriétés spectrales des sols arides appliquée à l'amélioration des indices de végétation obtenus par télédétection," Comptes Rendus de l'Académie des Sciences, vol. 312, no. 2, pp. 1385-1391, 1991.

[125] R. L. Pearson and L. D. Miller, "Remote mapping of standing crop biomass for estimation of the productivity of the shortgrass prairie," Remote Sensing of Environme, vol. 8, p. 1355, 1972.

[126] D. Haboudane, J. R. Miller, N. Tremblay, P. J. Zarco-Tejada, and L. Dextraze, "Integrated narrow-band vegetation indices for 
prediction of crop chlorophyll content for application to precision agriculture," Remote Sensing of Environment, vol. 81, no. 2-3, pp. 416-426, 2002.

[127] R. Pu and P. Gong, Advances in Environmental Remote Sensing, Higher Education, Beijing, 2011.

[128] G. S. Birth and G. R. McVey, "Measuring the color of growing turf with a reflectance spectrophotometer," Agronomy Journal, vol. 60, no. 6, p. 640, 1968.

[129] J. E. McMurtrey III, E. W. Chappelle, M. S. Kim, J. J. Meisinger, and L. A. Corp, "Distinguishing nitrogen fertilization levels in field corn (Zea mays L.) with actively induced fluorescence and passive reflectance measurements," Remote Sensing of Environment, vol. 47, no. 1, pp. 36-44, 1994.

[130] E. W. Chappelle, M. S. Kim, and J. E. McMurtrey, "Ratio analysis of reflectance spectra (RARS): an algorithm for the remote estimation of the concentrations of chlorophyll A, chlorophyll B, and carotenoids in soybean leaves," Remote Sensing of Environment, vol. 39, no. 3, pp. 239-247, 1992.

[131] B. Datt, "Remote sensing of chlorophyll a, chlorophyll b, chlorophyll $\mathrm{a}+\mathrm{b}$, and total carotenoid content in eucalyptus leaves," Remote Sensing of Environment, vol. 66, no. 2, pp. 111-121, 1998.

[132] A. Bannari, H. Asalhi, and P. M. Teillet, “Transformed difference vegetation index (TDVI) for vegetation cover mapping," in Proceedings of the IEEE International Geoscience and Remote Sensing Symposium IGARSS '02, pp. 3053-3055, Toronto, Canada, 2002.

[133] F. Baret, G. Guyot, and D. J. Major, “TSAVI: A vegetation index which minimizes soil brightness effects on LAI and APAR estimation," in Proceedings of the 12th Canadian Symposium on Remote Sensing Geoscience and Remote Sensing Symposium, pp. 1355-1358, IEEE, 1989.

[134] J. Rouse Jr., "Monitoring the vernal advancement and retrogradation (green wave effect) of natural vegetation," NASA Technical Reports Server, Tex, USA, 1974, https://ntrs.nasa.gov/search .jsp?R=19740022555.

[135] A. A. Gitelson, Y. J. Kaufman, R. Stark, and D. Rundquist, "Novel algorithms for remote estimation of vegetation fraction," Remote Sensing of Environment, vol. 80, no. 1, pp. 76-87, 2002.

[136] F. N. Kogan, "Application of vegetation index and brightness temperature for drought detection," Advances in Space Research, vol. 15, no. 11, pp. 91-100, 1995.

[137] A. F. Wolf, "Using WorldView-2 Vis-NIR multispectral imagery to support land mapping and feature extraction using normalized difference index ratios," in Proceedings of the 18th Annual Conference on Algorithms and Technologies for Multispectral, Hyperspectral, and Ultraspectral Imagery, Baltimore, Md, USA, 2012.

[138] C. D. Elvidge and Z. Chen, "Comparison of broad-band and narrow-band red and near-infrared vegetation indices," Remote Sensing of Environment, vol. 54, no. 1, pp. 38-48, 1995. 


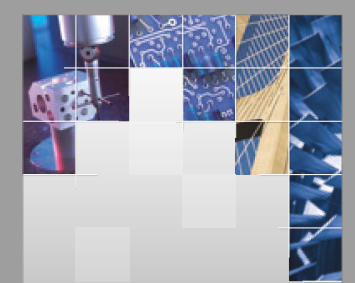

\section{Enfincering}
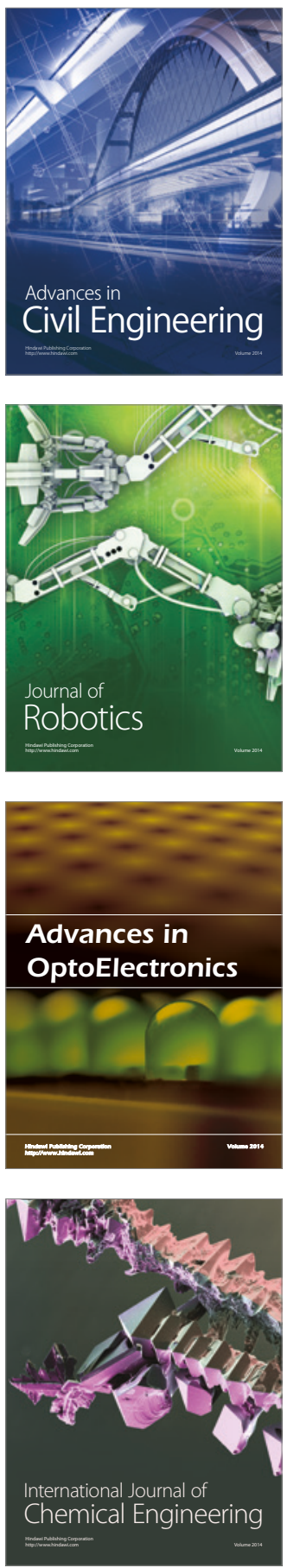

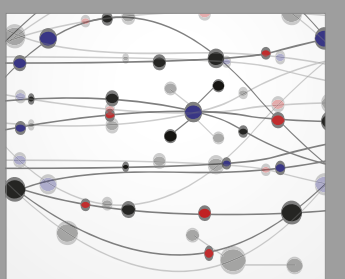

The Scientific World Journal

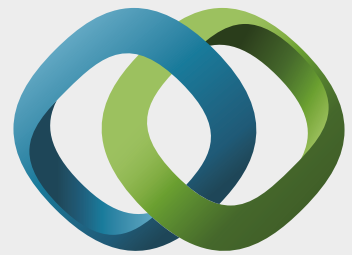

\section{Hindawi}

Submit your manuscripts at

https://www.hindawi.com
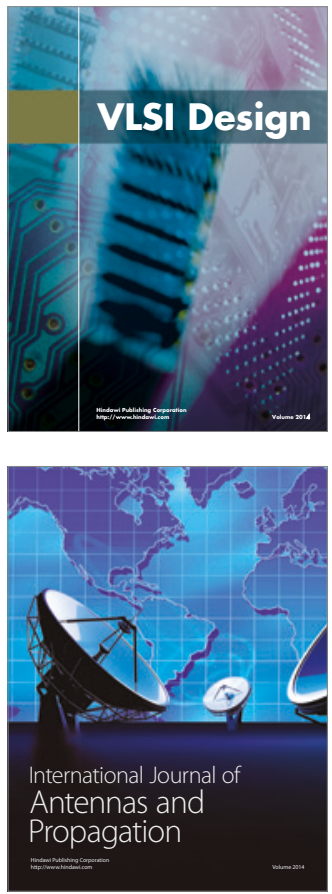

\section{Rotating}

Machinery
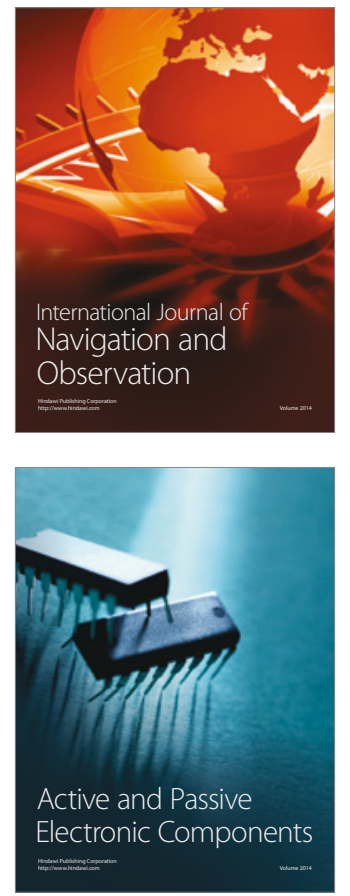
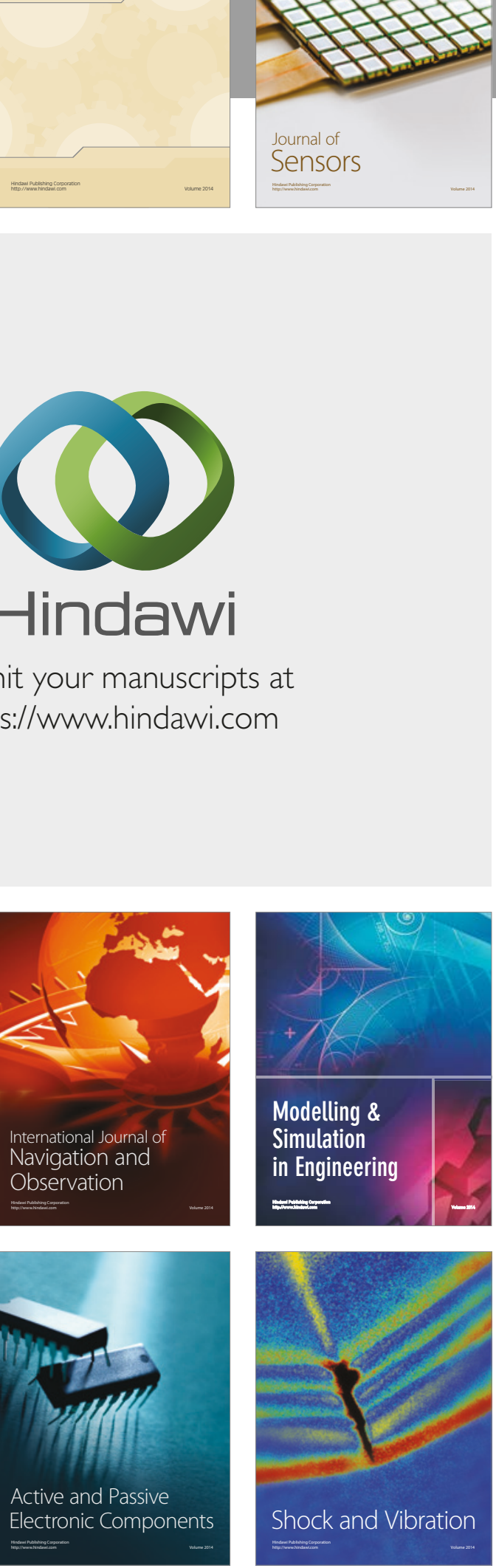
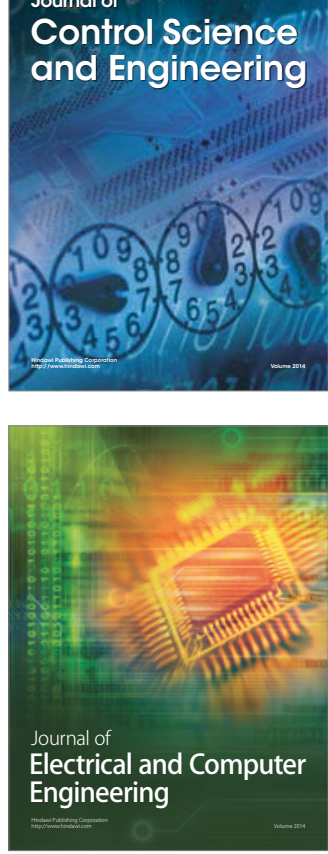

Distributed

Journal of

Control Science

and Engineering
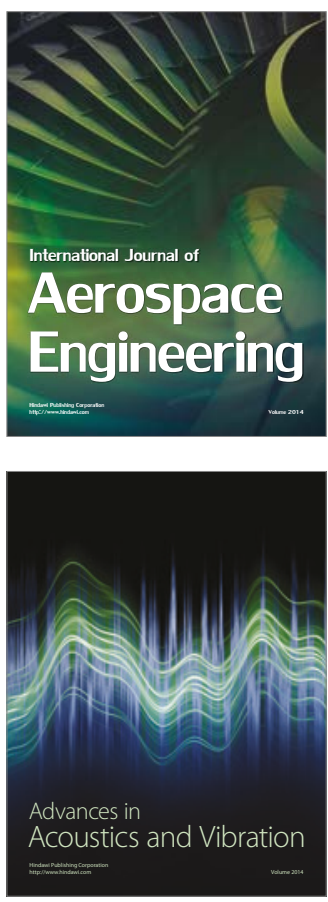

Sensor Networks 